\section{PHARMACOLOGIC INTERVENTION FOR ISCHEMIC BRAIN EDEMA AFTER RETROGRADE CEREBRAL PERFUSION}

Retrograde cerebral perfusion has recently been the focus of interest as a simple new technique of brain protection during aortic arch operations. We undertook the experimental protocol of 120 minutes of retrograde cerebral perfusion followed by antegrade reperfusion. Eighteen mongrel dogs were used. Retrograde cerebral perfusion was maintained at a flow rate of 150 to $250 \mathrm{ml} / \mathrm{min}$ to keep the perfusion pressure from 15 to $25 \mathrm{~mm} \mathrm{Hg}$. Animals were divided into three groups as follows: in group I, no treatment was received during and after retrograde cerebral perfusion; in group II, mannitol ( $2 \mathrm{gm} / \mathrm{kg}$ ) was administered before cardiopulmonary bypass was restarted; and in group III, antivasospastic substance (1,2-bis[nicotinamido]-propane) was continuously injected during and after retrograde cerebral perfusion ( $1 \mathrm{mg} / \mathrm{kg}$ per minute). Cerebral blood flow decreased during retrograde cerebral perfusion in all three groups. Cerebrovascular resistance showed marked increases 30 and 60 minutes after cardiopulmonary bypass was restarted in group I compared with the values in groups II and III (group I: $3.35 \pm 0.73$ and $5.00 \pm 1.57 \mathrm{~mm} \mathrm{Hg} / \mathrm{ml}$ per 100 gm per minute; group II: $1.30 \pm 0.33$ and $1.03 \pm 0.17 \mathrm{~mm} \mathrm{Hg} / \mathrm{ml}$ per 100 gm per minute; group III: $1.24 \pm 0.41$ and $0.98 \pm 0.24 \mathrm{~mm} \mathrm{Hg} / \mathrm{ml}$ per $100 \mathrm{gm}$ per minute). The oxygen extraction level was reduced by cooling, but it rose to a higher level as a result of significant desaturation of returned blood even in deep hypothermia during retrograde cerebral perfusion. Both cerebral metabolic rate of oxygen and cerebral metabolic rate of glucose remained at low levels during retrograde cerebral perfusion. Ratios of cerebral blood flow to cerebral metabolic rate of oxygen and cerebral blood flow to cerebral metabolic rate of glucose were markedly reduced during retrograde cerebral perfusion. Intracranial pressure showed significant increases 30 and 60 minutes after cardiopulmonary bypass was restarted in group I compared with values in group II or group III (group I: $22.7 \pm 2.8$ and $20.6 \pm 5.1 \mathrm{~mm} \mathrm{Hg}$; group II: $6.3 \pm 1.8$ and $5.3 \pm 1.3 \mathrm{~mm} \mathrm{Hg}$; group III: $4.2 \pm 1.7$ and $7.7 \pm 2.8 \mathrm{~mm} \mathrm{Hg})$. Water content of the brain tissue in group $\mathrm{I}(77.54 \% \pm 0.29 \%)$ was significantly higher than that in group II $(74.71 \% \pm 0.76 \%)$ or group III $(74.14 \% \pm$ $0.48 \%$ ). These data suggest that the supply of oxygen or glucose by retrograde cerebral perfusion is not enough to maintain sufficient cerebral metabolism, which may cause brain edema during antegrade reperfusion. Therefore cerebral protection via pharmacologic agents is recommended to prevent neurologic complications during aortic arch operations with the use of retrograde cerebral perfusion. (J THORAC CARDIOVASC SURG 1995;109:1173-81)

Naoki Yoshimura, MD, Masayoshi Okada, MD, Toshiaki Ota, MD, and Hideaki Nohara, MD, Kobe, Japan
A neurysms of the thoracic aorta including the aortic arch result in the highest rate of mortality and morbidity among all aneurysms, and protection

From the Department of Surgery, Division Il, Kobe University, School of Medicine, Kobe, Japan.

Received for publication April 21, 1994.

Accepted for publication Sept. 19, 1994.

Address for reprints: Naoki Yoshimura, MD, Department of Surgery, Division II, Kobe University, School of Medicine, 7-5-2, Kusunoki-cho, Chuo-ku, Kobe 650, Japan.

Copyright (C) 1995 by Mosby-Year Book, Inc.

$0022-5223 / 95 \$ 3.00+0 \quad \mathbf{1 2 / 1 / 6 0 6 9 3}$ of the brain while cerebral blood flow is interrupted is considered to be the most important priority during aortic arch operations. ${ }^{1}$ As supportive techniques, deep hypothermic circulatory arrest, ${ }^{2,3}$ selective cerebral perfusion, 4,5 and retrograde cerebral perfusion (RCP) ${ }^{6,7}$ have been used during the period of arch vessel occlusion.

Among these techniques, RCP has recently been the focus of interest as a simple new technique of brain protection during aortic arch operation. ${ }^{8-10}$ This method may be useful because it does not require cannulation and crossclamping of arch ves- 


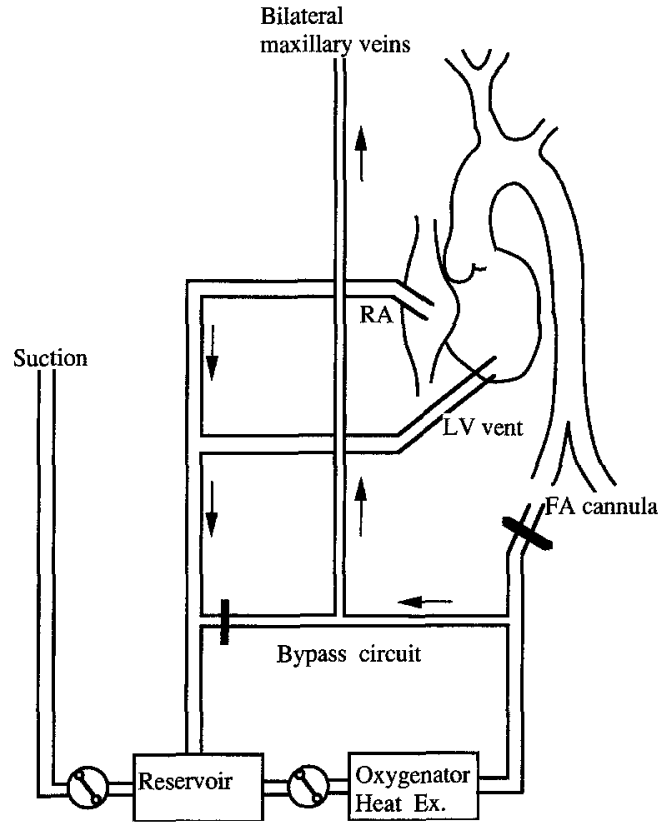

Fig. 1. Experimental circuit. $F A$, Femoral artery; $L V$, left ventricle; $R A$, right atrium; Heat $E x$, heat exchanger.

sels, and it may enhance cerebral protection during circulatory arrest. However, it is not clear whether this method provides adequate cerebral oxygenation or how long it can be done safely, ${ }^{11}$ and therefore further studies are necessary to clarify these problems. We undertook the experimental protocol of 120 minutes of RCP followed by 60 minutes of antegrade reperfusion with two objectives: (1) to define the pattern of cerebral response to RCP and (2) to evaluate whether pharmacologic intervention enhances neuronal recovery after RCP. In this study, the protocol and techniques were designed to duplicate those used in a routine clinical setting.

\section{Material and methods}

All animals received humane care in compliance with the "Principles of Laboratory Animal Care" formulated by the National Society for Medical Research and the "Guide for the Care and Use of Laboratory Animals" prepared by the Institute of Laboratory Animal Resources and published by the National Institutes of Health (NIH Publication No. 86-23, revised 1985).

Animal preparation. Eighteen mongrel dogs weighing 10 to $15 \mathrm{~kg}$ were used in this study. Anesthesia was induced with ketamine hydrochloride $(10 \mathrm{mg} / \mathrm{kg})$ intramuscularly and thiamylal sodium $(5 \mathrm{mg} / \mathrm{kg})$ intravenously. Tracheostomy was done, and the animals were maintained on positive-pressure ventilation with $1 \%$ enflurane and $99 \%$ oxygen and paralyzed with pancuronium bromide. The lungs were not inflated during cardiopulmonary bypass (CPB) or RCP. Anesthesia was maintained with pentobarbital sodium ( $1 \mathrm{mg} / \mathrm{kg}$ per hour) through a catheter placed in the right carotid artery until RCP was started. A nasopharyngeal temperature probe was set in place, and bilateral internal maxillary vein catheters were inserted for blood perfusion and monitoring of perfusion pressure during RCP. A subdural catheter was inserted through a burr hole in the skull for intracranial pressure monitoring.

Extracorporeal circulation technique. A median sternotomy was done, and each animal received heparin sodium $(300 \mathrm{U} / \mathrm{kg})$ intravenously. The left femoral artery and right atrium were cannulated, and CPB was established at a flow rate of $70 \mathrm{ml} / \mathrm{kg}$ per minute during cooling and rewarming. A cannula was passed from the left atrium into the left ventricle to permit decompression of the left side of the heart during extracorporeal circulation. RCP was established with blood perfusion through the bilateral internal maxillary veins and drainage through the right atrium cannula and left ventricle venting cannula (Fig. 1). $\mathrm{RCP}$ was maintained at a flow rate of 150 to $250 \mathrm{ml} / \mathrm{min}$ to keep the perfusion pressure from 15 to $25 \mathrm{~mm} \mathrm{Hg}$. The extracorporeal circulation circuit consisted of a nonpulsatile roller pump and a Shiley S-070/S oxygenator (Shiley Inc., Irvine, Calif.) primed with lactated Ringer's solution, $1000 \mathrm{U}$ heparin sodium, $3.5 \mathrm{gm}$ sodium bicarbonate, and $300 \mathrm{ml}$ blood from another dog. A CDI-300 continuous in-line blood gas analyzer (3M Healthcare, Irvine, Calif.) was used to control circuit blood gas levels. ${ }^{12}$ No pharmacologic agents were given to control blood pressure during this study.

Cerebral blood flow and cerebrovascular resistance. Cerebral blood flow (CBF) was measured simultaneously by the hydrogen clearance method with a UH meter (Unique Medical Co., Tokyo, Japan) and laser Doppler flowmetry with the Peri Flux PF3 machine (Perimed Co., Stockholm, Sweden). A hydrogen electrode and a laser Doppler probe were inserted into the cerebral cortex of the parietal lobe through the burr holes in the skull.

Cerebrovascular resistance (CVR) was calculated as follows: CVR (millimeters of Mercury per milliiter per $100 \mathrm{gm})=($ mean arterial pressure - mean internal maxillary venous pressure)/CBF (during $\mathrm{CPB}$ ), or $\mathrm{CVR}=$ (mean internal maxillary venous pressure - mean arterial pressure)/CBF (during RCP).

Cerebral metabolism. During the experimental protocol, perfused and returned blood were sampled to measure cerebral metabolism. Perfused blood was obtained from the extracorporeal circulation circuit. Returned blood was obtained from the internal maxillary venous catheter during CPB or from the carotid arterial catheter during RCP. Cerebral metabolic rate of oxygen $\left(\mathrm{CMRO}_{2}\right)$ and cerebral metabolic rate of glucose (CMRGlu) were calculated as follows: $\mathrm{CMRO}_{2}$ (milliliters per 100 gm per minute $)=\mathrm{CBF} \times\left(\right.$ perfused $\mathrm{O}_{2}$ content - returned $\mathrm{O}_{2}$ content) $/ 100$, and CMRGlu (milligrams per 100 gm per minute $)=\mathrm{CBF} \times($ perfused glucose level - returned glucose level) $/ 100$.

Perfused and returned blood $\mathrm{O}_{2}$ content was measured with an ABL3 instrument (Radiometer, Copenhagen, Denmark), and glucose levels were measured with a TOECHO III instrument (Kodama Co., Tokyo, Japan). 
Table I. Mean arterial pressure, internal maxillary venous pressure, nasopharyngeal temperature, and parameters of the perfused blood during the protocol

\begin{tabular}{|c|c|c|c|c|c|c|c|c|c|}
\hline \multirow[b]{2}{*}{ Variable } & \multicolumn{2}{|c|}{$C P B$} & \multicolumn{4}{|c|}{$R C P$} & \multicolumn{3}{|c|}{ reCPB } \\
\hline & $10 \mathrm{~min}$ & $60 \mathrm{~min}$ & $30 \mathrm{~min}$ & $60 \mathrm{~min}$ & $90 \mathrm{~min}$ & $120 \mathrm{~min}$ & $10 \mathrm{~min}$ & $30 \mathrm{~min}$ & $60 \mathrm{~min}$ \\
\hline \multicolumn{10}{|c|}{ MAP (mm Hg) } \\
\hline Group I & $70 \pm 12$ & $60 \pm 8$ & $3 \pm 1$ & $3 \pm 1$ & $3 \pm 1$ & $3 \pm 1$ & $73 \pm 12$ & $78 \pm 10$ & $67 \pm 8$ \\
\hline Group II & $51 \pm 7$ & $49 \pm 8$ & $4 \pm 2$ & $4 \pm 2$ & $4 \pm 2$ & $4 \pm 2$ & $46 \pm 4$ & $54 \pm 7$ & $50 \pm 6$ \\
\hline Group III & $89 \pm 18$ & $47 \pm 7$ & $2 \pm 1$ & $2 \pm 1$ & $2 \pm 1$ & $1 \pm 1$ & $59 \pm 10$ & $57 \pm 5$ & $57 \pm 6$ \\
\hline \multicolumn{10}{|c|}{ IMVP (mm Hg) } \\
\hline Group I & $11 \pm 2$ & $8 \pm 2$ & $24 \pm 3$ & $22 \pm 3$ & $22 \pm 3$ & $22 \pm 3$ & $10 \pm 1$ & $11 \pm 1$ & $12 \pm 1$ \\
\hline Group II & $12 \pm 1$ & $11 \pm 1$ & $22 \pm 1$ & $21 \pm 1$ & $22 \pm 1$ & $22 \pm 1$ & $11 \pm 3$ & $13 \pm 1$ & $13 \pm 3$ \\
\hline Group III & $7 \pm 1$ & $7 \pm 2$ & $16 \pm 2$ & $17 \pm 3$ & $16 \pm 2$ & $15 \pm 2$ & $12 \pm 1$ & $13 \pm 1$ & $13 \pm 1$ \\
\hline \multicolumn{10}{|c|}{ NP temp. $\left({ }^{\circ} \mathrm{C}\right)$} \\
\hline Group I & $34.9 \pm 0.6$ & $21.3 \pm 0.7$ & $20.1 \pm 0.5$ & $20.0 \pm 1.1$ & $19.7 \pm 1.2$ & $19.8 \pm 1.0$ & $21.2 \pm 0.9$ & $29.3 \pm 2.3$ & $35.9 \pm 0.5$ \\
\hline Group II & $34.6 \pm 0.6$ & $20.1 \pm 0.4$ & $20.0 \pm 0.9$ & $19.6 \pm 1.1$ & $19.3 \pm 1.3$ & $19.2 \pm 1.4$ & $19.3 \pm 1.7$ & $28.5 \pm 1.7$ & $34.9 \pm 0.7$ \\
\hline Group III & $33.4 \pm 0.8$ & $19.4 \pm 0.4$ & $17.5 \pm 0.7$ & $17.1 \pm 1.0$ & $16.5 \pm 1.0$ & $16.2 \pm 1.0$ & $17.8 \pm 0.9$ & $28.1 \pm 1.4$ & $35.3 \pm 0.7$ \\
\hline \multicolumn{10}{|l|}{$\mathrm{Hb}(\mathrm{gm} / \mathrm{dl})$} \\
\hline Group I & $14.6 \pm 0.9$ & $15.2 \pm 0.9$ & $15.0 \pm 0.9$ & $14.3 \pm 0.7$ & $14.8 \pm 0.5$ & $13.5 \pm 0.7$ & $14.2 \pm 0.4$ & $14.4 \pm 0.4$ & $15.7 \pm 0.6$ \\
\hline Group II & $14.4 \pm 0.9$ & $13.8 \pm 0.8$ & $13.6 \pm 0.6$ & $12.9 \pm 0.6$ & $13.2 \pm 0.6$ & $12.7 \pm 0.8$ & $12.2 \pm 0.9$ & $12.1 \pm 0.7$ & $12.2 \pm 0.7$ \\
\hline Group III & $13.8 \pm 1.5$ & $13.5 \pm 1.3$ & $13.1 \pm 1.4$ & $12.9 \pm 1.6$ & $13.2 \pm 1.5$ & $13.0 \pm 1.5$ & $12.8 \pm 1.8$ & $13.4 \pm 1.5$ & $13.5 \pm 1.4$ \\
\hline \multicolumn{10}{|c|}{$\mathrm{O}_{2}$ cont. (vol \%) } \\
\hline Group I & $21.7 \pm 1.3$ & $23.2 \pm 1.3$ & $23.2 \pm 1.3$ & $22.2 \pm 0.9$ & $22.9 \pm 0.7$ & $21.6 \pm 0.5$ & $21.7 \pm 0.7$ & $21.8 \pm 0.6$ & $23.5 \pm 0.9$ \\
\hline Group II & $21.3 \pm 1.4$ & $20.6 \pm 1.0$ & $21.1 \pm 0.8$ & $20.0 \pm 0.7$ & $20.6 \pm 0.8$ & $19.9 \pm 1.2$ & $19.1 \pm 1.3$ & $18.9 \pm 1.1$ & $18.7 \pm 1.0$ \\
\hline Group III & $20.9 \pm 1.8$ & $20.6 \pm 2.0$ & $20.3 \pm 2.2$ & $19.5 \pm 2.7$ & $20.4 \pm 2.2$ & $20.1 \pm 2.2$ & $19.8 \pm 2.6$ & $20.0 \pm 2.2$ & $20.1 \pm 2.0$ \\
\hline \multicolumn{10}{|c|}{ Glucose (mg/dl) } \\
\hline Group I & $203 \pm 14$ & $215 \pm 19$ & $226 \pm 13$ & $243 \pm 15^{*}$ & $215 \pm 17$ & $220 \pm 12$ & $239 \pm 22$ & $274 \pm 34$ & $237 \pm 45$ \\
\hline Group II & $190 \pm 23$ & $202 \pm 32$ & $190 \pm 14$ & $186 \pm 9^{*}$ & $184 \pm 11$ & $181 \pm 15$ & $189 \pm 14$ & $233 \pm 23$ & $247 \pm 37$ \\
\hline Group III & $189 \pm 19$ & $172 \pm 9$ & $215 \pm 9$ & $202 \pm 6$ & $223 \pm 25$ & $212 \pm 30$ & $192 \pm 19$ & $269 \pm 30$ & $294 \pm 36$ \\
\hline
\end{tabular}

reCBP, Restarting of $\mathrm{CPB} ; M A P$, Mean arterial pressure; $I M V P$, internal maxillary venous pressure; $N P$ temp., nasopharyngeal temperature; $H b$, hemoglobin; $\mathrm{O}_{2}$ cont., oxygen content.

${ }^{*} p<0.05$.

Experimental protocol. CPB was initiated at a flow rate of $70 \mathrm{ml} / \mathrm{kg}$ per minute, and cooling was done to a $20^{\circ} \mathrm{C}$ nasopharyngeal temperature with an average cooling time of $38.3 \pm 1.7$ minutes. After a brief period of circulatory arrest, RCP was started and continued for 120 minutes, Then CPB was reestablished, and rewarming was done over 60 minutes to $36^{\circ} \mathrm{C}$. When the temperature reached $36^{\circ} \mathrm{C}$, animals were weaned from CPB.

Animals were randomly assigned to one of three experimental groups: in group I ( $n=6$, control group), no treatment was received during and after RCP; in group II $(n=6)$, mannitol $(2 \mathrm{gm} / \mathrm{kg})$ was administered by bolus injection into the oxygenator reservoir before CPB was restarted; and in group III $(n=6)$, antivasospastic substance (1,2-bis[nicotinamido]-propane) ${ }^{13}$ was injected continuously into the internal maxillary veins during RCP and into the right carotid artery during rewarming by $\mathrm{CPB}$ (1 $\mathrm{mg} / \mathrm{kg}$ per minute).

Data were collected at nine points during the experimental protocol as follows: 10 and 60 minutes after the initiation of CPB (before and after cooling); 30, 60, 90, and 120 minutes after the initiation of RCP; and 10, 30, and 60 minutes after the restarting of CPB (before, during, and after rewarming).

When CPB was terminated, the animal was immediately killed and the brain was removed to evaluate the degree of brain edema. Water content was calculated from the comparison of dry and wet weights.

Statistical analysis. All results are expressed as mean plus or minus the standard error of the mean. Values were compared at the various times by analysis of variance with repeated measures, and differences at each time were tested by factorial analysis of variance. When the $F$ ratio of the analysis of variance was significant, the differences were tested by Scheffe's test. Statistical significance was tested at the $95 \%$ confidence level.

\section{Results}

Table I shows mean arterial pressure, mean internal maxillary venous pressure, nasopharyngeal temperature and hemoglobin level, oxygen content, or glucose level of the perfused blood measured for each animal during the experimental protocol. During the RCP period, internal maxillary venous pressure exceeded the arterial pressure. The pressure gradient between the internal maxillary veins and systemic artery caused retrograde $\mathrm{CBF}$, which was evidenced by "dark" blood with a low oxygen level being returned to the carotid artery. Nasopharyn- 


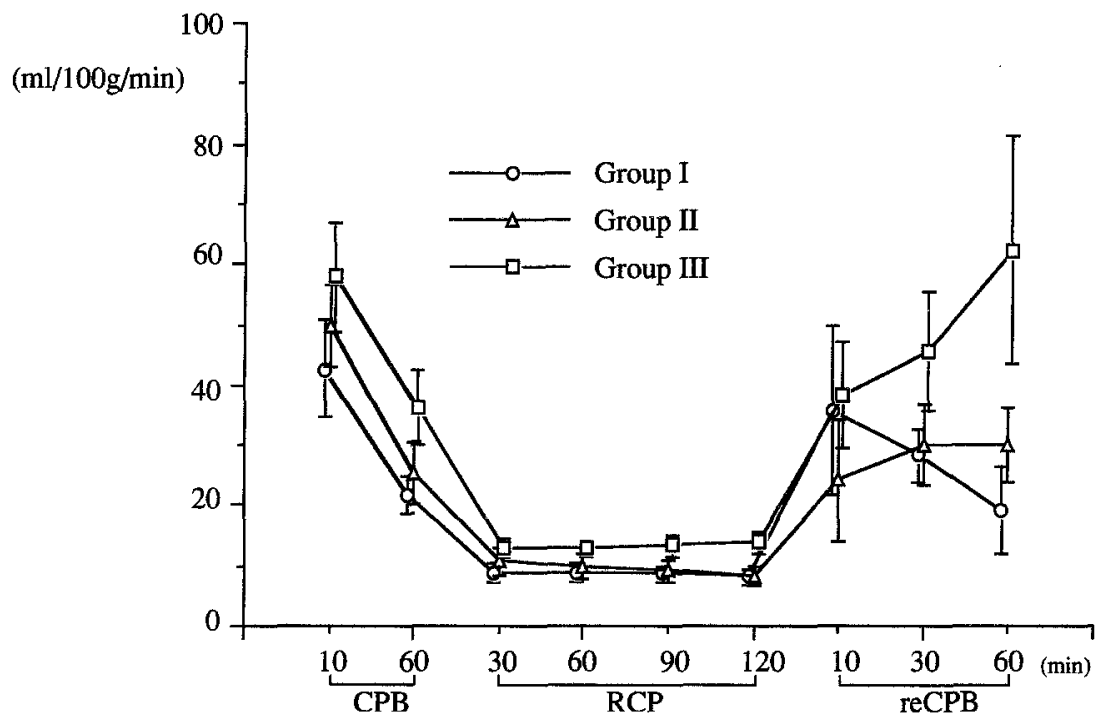

Fig. 2. Changes of $\mathrm{CBF}$ during experimental protocol, re $C P B$, Restarting of $\mathrm{CPB}$.

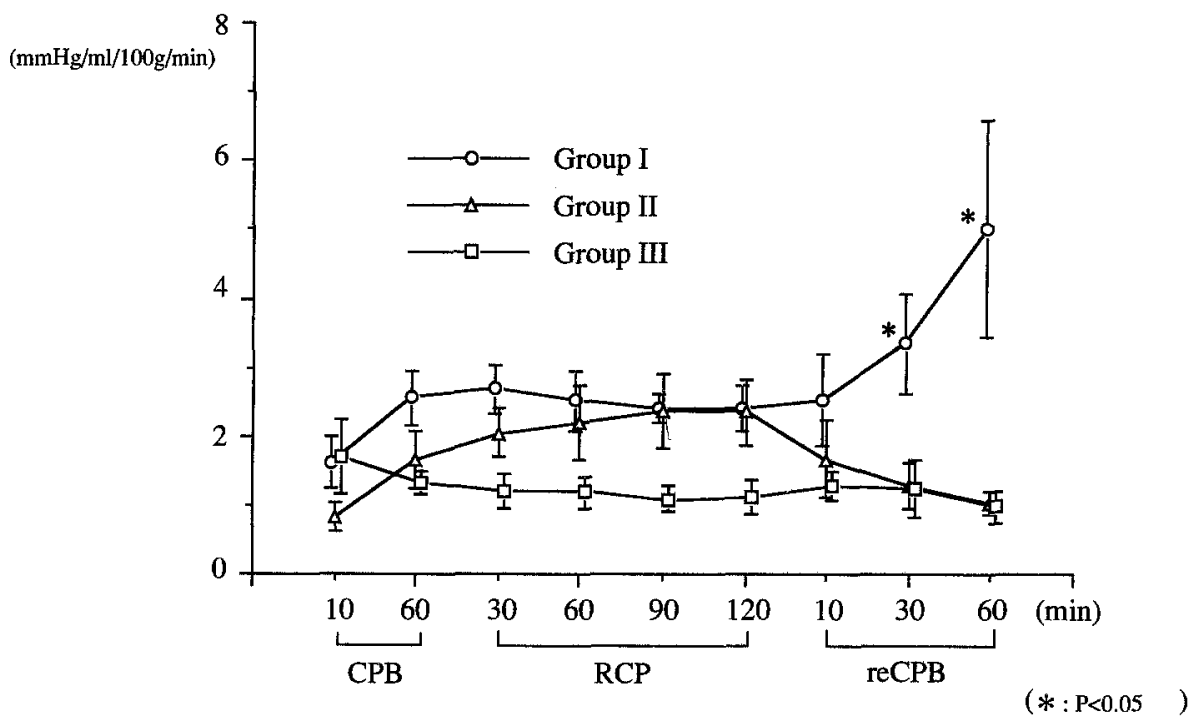

Fig. 3. Changes of $\mathrm{CVR}$ during experimental protocol. reCPB, Restarting of $\mathrm{CPB}$.

geal temperature gradually decreased during the RCP period, which is thought to be one of the protective effects of RCP. A statistically significant difference in glucose level 60 minutes after initiation of RCP was observed between group I and group II, but this difference was probably of no physiologic importance. There were no statistically significant differences among the three groups in the other variables examined.

CBF and CVR. The changes of CBF and CVR are shown in Figs. 2 and 3, respectively. In all three groups, $\mathrm{CBF}$ decreased at $20^{\circ} \mathrm{C}$ nasopharyngeal temperature before RCP and decreased still more during RCP. CVR showed a marked increase after CPB was restarted in group I, and it was significantly higher than the values in groups II and III at 30 and 60 minutes after restarting of CPB (group I: $3.35 \pm$ 0.73 and $5.00 \pm 1.57 \mathrm{~mm} \mathrm{Hg} / \mathrm{ml}$ per $100 \mathrm{gm}$ per minute; group II: $1.30 \pm 0.33$ and $1.03 \pm 0.17 \mathrm{~mm}$ $\mathrm{Hg} / \mathrm{ml}$ per $100 \mathrm{gm}$ per minute; group III: $1.24 \pm 0.41$ and $0.98 \pm 0.24 \mathrm{~mm} \mathrm{Hg} / \mathrm{ml}$ per 100 gm per minute).

Cerebral metabolism. Oxygen and glucose extraction levels are shown in Fig. 4, $A$ and $B$. The oxygen extraction level was reduced by cooling, but 
it rose to a higher level as a result of significant desaturation of returned blood even in deep hypothermia during RCP. The oxygen extraction level showed a rapid decrease after $\mathrm{CPB}$ was restarted and gradually increased during rewarming. The glucose extraction level was also observed to increase during RCP. Both $\mathrm{CMRO}_{2}$ and CMRGlu were reduced by cooling and remained at low levels during RCP. Although there were no significant differences among the three groups during the experimental protocol, $\mathrm{CMRO}_{2}$ and $\mathrm{CMRG}$ lu were not elevated by rewarming during $\mathrm{CPB}$ in group I (Fig. 4, $C$ and $D$ ). CBF/CMRO ${ }_{2}$ and $\mathrm{CBF} / \mathrm{CMRGlu}$ were elevated during cooling and early rewarming states. However, these values were markedly reduced during RCP even in deep hypothermia (Fig. $4, E$ and $F$ ).

Intracranial pressure. Intracranial pressure did not increase by the end of RCP. After CPB was restarted, intracranial pressure did not increase in dogs that received mannitol (group II) or antivasospastic substance (group III), whereas in untreated dogs (group I), it showed significant increases 30 and 60 minutes after CPB was restarted (group I: $22.7 \pm 2.8$ and $20.6 \pm 5.1 \mathrm{~mm} \mathrm{Hg}$; group II: $6.3 \pm$ 1.8 and $5.3 \pm 1.3 \mathrm{~mm} \mathrm{Hg}$; group III: $4.2 \pm 1.7$ and $7.7 \pm 2.8 \mathrm{~mm} \mathrm{Hg}$ ) (Fig. 5).

Water content of the brain tissue. Water content of the brain tissue in dogs that received mannitol (group II: $74.71 \% \pm 0.76 \%$ ) or antivasospastic substance (group III: $74.14 \% \pm 0.48 \%$ ) was significantly lower than that in untreated dogs (group I: $77.54 \% \pm 0.29 \%$ ) (Fig. 6).

\section{Discussion}

RCP via the superior vena cava is a new technique of brain protection during aortic arch operation and is widely used today. ${ }^{6-10} \mathrm{RCP}$ is a simple method that does not need special equipment, cannulation, or clamping of the arch vessels. RCP can flush out air and atheromatous debris in the cerebral vessels and maintain the desired cerebral temperature by cooling of the perfused blood. ${ }^{7,9}$ Furthermore, it may reduce ischemic damage to the brain by providing oxygen, glucose, ${ }^{11}$ and cerebral protective agents as a form of pharmacologic intervention. However, it is not clear whether this method provides adequate cerebral oxygenation or how long it can be done safely. ${ }^{11}$ In this study, we report results from our measurements of CBF, CVR, parameters of cerebral metabolism, intracranial pressure, and water content of the brain tissue. Moreover, we assessed the effects of pharmacologic intervention for cerebral protection during and after RCP. In this experiment, an RCP period of 120 minutes was selected to simulate most aortic arch operations, and blood was perfused via the bilateral internal maxillary veins to avoid venous valves that would interfere with retrograde perfusion. ${ }^{11}$

Values for $\mathrm{CBF}, \mathrm{CMRO}_{2}$, and $\mathrm{CMRGlu}$ were markedly reduced by hypothermic CPB as was expected. ${ }^{14-17}$ We found that half of the CBF was provided during $\mathrm{RCP}$ compared with that during CPB with hypothermia. This result was in accord with that of Usui and associates. ${ }^{11}$ Values for $\mathrm{CMRO}_{2}$ and $\mathrm{CMRGlu}$ showed no remarkable changes during 120 minutes of RCP. However, it is thought that cerebral metabolism during $\mathrm{RCP}$ is insufficient to prevent cerebral injury. During RCP, returned blood sampled from the carotid artery revealed marked desaturation, which reflected an elevation of oxygen extraction. Increased oxygen extraction would be the compensatory response when oxygen demand is much higher than the oxygen supply. ${ }^{16}$ The relationship between the changes in CBF and cerebral metabolism can be summarized by the $\mathrm{CBF} / \mathrm{CMRO}_{2}$ ratio. ${ }^{16,17}$ The $\mathrm{CBF} / \mathrm{CMRO}_{2}$ ratio increased during hypothermic $\mathrm{CPB}$, showing so-called "luxury perfusion." On the other hand, it showed a significant decrease during RCP even with deep hypothermia. The discordance between $\mathrm{CBF}$ and cerebral metabolism suggests that a disturbance in cerebral autoregulation occurs during RCP.

In the untreated group (group I), CBF gradually decreased and CVR significantly increased after CPB was restarted. Mezrow and associates ${ }^{17}$ and Anstadt and associates ${ }^{18}$ have both demonstrated a similar phenomenon after deep hypothermic circulatory arrest. Mezrow and associates ${ }^{17}$ suggested that the late reperfusion period after hypothermic circulatory arrest is the time when the brain is particularly vulnerable to injury. In our study, intracranial pressure showed a significant increase simultaneous with the elevation of CVR in untreated dogs. Moreover, water content of the brain tissue in untreated dogs (group I) was significantly higher than that in dogs that received mannitol (group II) or antivasospastic substance (group III). These results suggest that brain edema might develop during the reperfusion period after RCP.

Recently, three mechanisms of ischemic brain damage have been the focus of interest. These are elevation of intracellular $\mathrm{Ca}^{2+}$, excessive acidosis, 

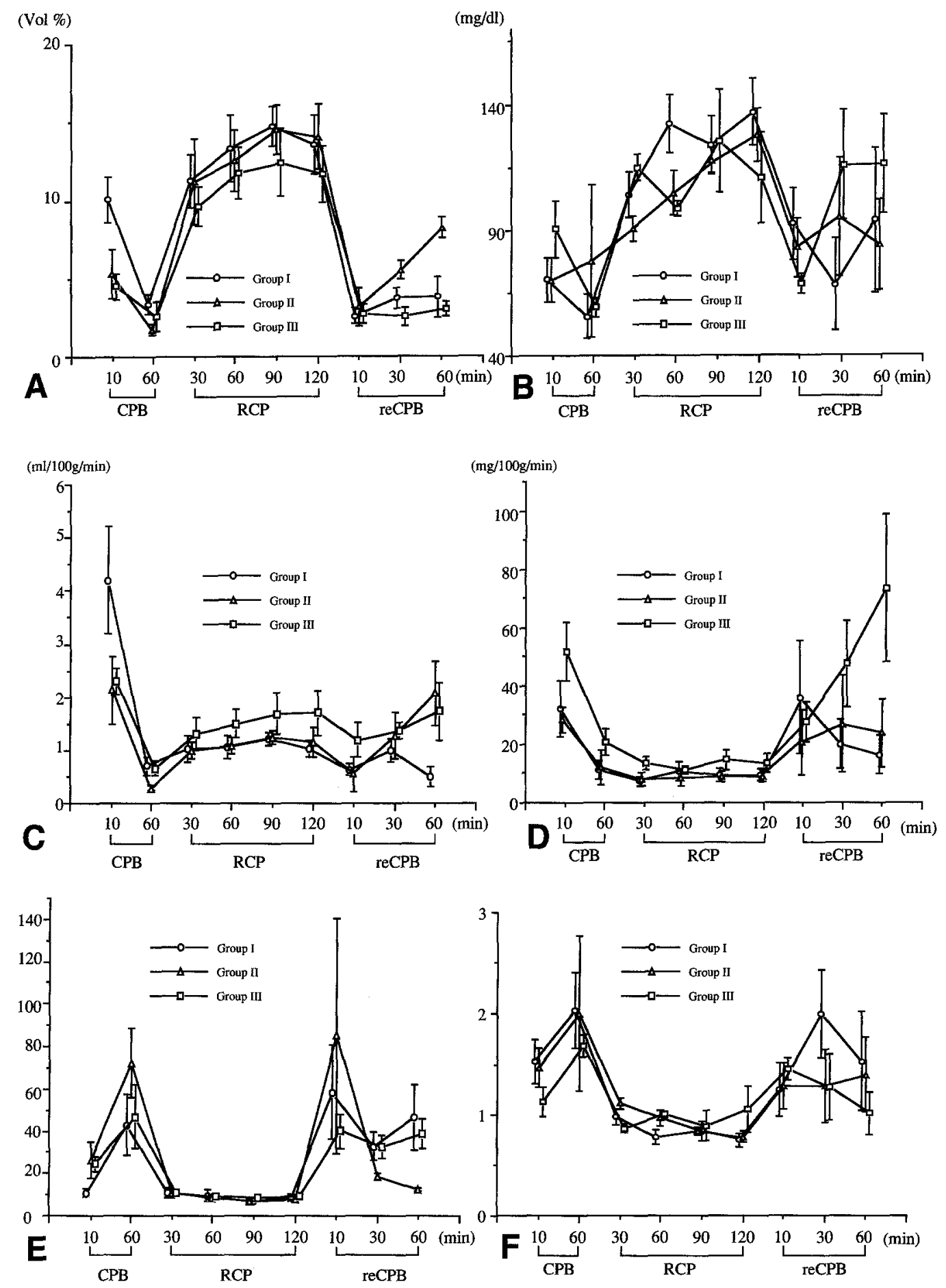

Fig. 4. Changes of cerebral metabolism during experimental protocol. $\mathbf{A}, \mathrm{O}_{2}$ extraction. B, Glucose extraction. $\mathbf{C}, \mathrm{CMRO}_{2}$. D, CMRGlu. E, $\mathrm{CBF} / \mathrm{CMRO}_{2}$ ratio. $\mathbf{F}, \mathrm{CBF} / \mathrm{CMRGlu}$ ratio. reCPB, Restarting of CPB.

and enhanced production of free radicals. ${ }^{19}$ Abnormal influx of $\mathrm{Ca}^{2+}$ occurs via activation of receptors by glutamate and associated excitatory amino acids. ${ }^{19,20}$ An excessive $\mathrm{Ca}^{2+}$ level causes overactiva- tion of phospholipases and proteases, which results in cell injury. ${ }^{21}$ Excessive acidosis enhances development of edema by inducing $\mathrm{Na}^{+}$and $\mathrm{Cl}^{-}$accumulation via coupled $\mathrm{Na}^{+} / \mathrm{H}^{+}$and $\mathrm{Cl}^{-} / \mathrm{HCO}_{3}{ }^{-}$ex- 


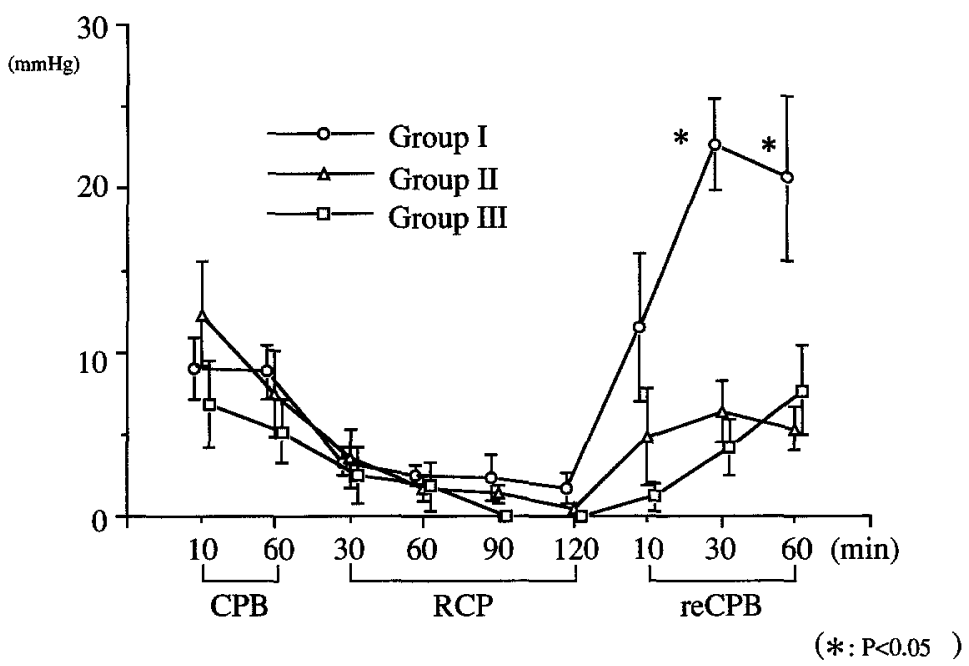

Fig. 5. Changes of intracranial pressure during experimental protocol. reCPB, Restarting of CPB.

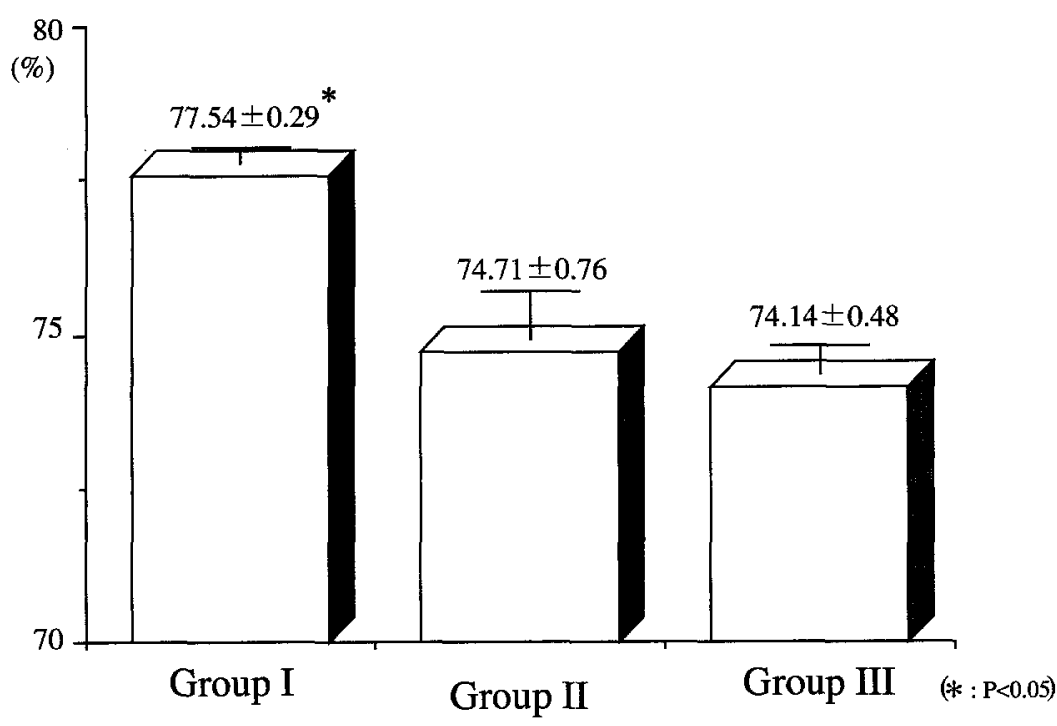

Fig. 6. Water content of brain tissue.

change. ${ }^{19}$ Although free radicals have been widely recognized as factors responsible for tissue injury after reperfusion, their role in the pathogenesis of brain damage after sustained ischemia and reperfusion has not been clearly understood. Recent studies revealed that free radicals primarily affect microvessels and increase microvascular permeability, which causes ischemic brain edema. ${ }^{19,22,23}$ On the basis of these findings, numerous trials of pharmacologic intervention, including use of calcium antagonists, ${ }^{21}$ glutamate receptor blockers, ${ }^{20,24,25}$ and free radical scavengers, ${ }^{13,23,26}$ have been made to ameliorate ischemic brain damage.
In this study, we selected mannitol and antivasospastic substance ${ }^{13}$ as cerebral protective agents. It is well accepted that water supply and brain cell damage are prerequisites for the development of brain edema and that the blockade of such water supply or inhibition of brain cell damage may prevent its occurrence. Mannitol, a hyperosmotic agent that can preserve water in the vascular lumen, may prevent the development of ischemic brain edema. ${ }^{27}$ In addition, it is known that mannitol shows the effect of a free radical scavenger, which may enhance the protective effect for brain tissue. ${ }^{28}$ Antivasospastic substance is a free-radical scavenger that 
is currently being subjected to clinical trials as a cerebral protective agent that may inhibit the development of ischemic brain edema. Koide and associates ${ }^{22}$ demonstrated that the eicosanoids, which are the products derived from the arachidonate cascade, synthetic capacity in the cerebral microvessels are enhanced after ischemia probably because of generation of free radicals, as well as the increased availability of free arachidonate, and that this process is related to the increase in the permeability of the blood-brain barrier to sodium. It is thought that antivasospastic substance suppresses the increased influx of water and sodium across the blood-brain barrier by the inhibition of increased production of eicosanoids in the cerebral microvessels. ${ }^{13}$ Our experimental study suggests that mannitol and antivasospastic substance may be useful pharmacologic agents even during deep hypothermic RCP; however, their therapeutic value needs to be further examined especially in deep hypothermia.

In summary, RCP is a useful technique for cerebral protection during aortic arch operation. However, the supply of oxygen or glucose by RCP is not enough to maintain sufficient cerebral metabolism, which may cause brain edema after antegrade cerebral blood perfusion is restarted. Therefore cerebral protection via pharmacologic agents (such as mannitol or antivasospastic substance) is recommended to prevent neurologic complications during aortic arch operation with the use of RCP.

\section{REFERENCES}

1. Laas J, Jurmann MJ, Heinemann M, Borst HG. Advances in aortic arch surgery. Ann Thorac Surg 1992;53:227-32.

2. Svensson LG, Crawford ES, Hess KR, et al. Deep hypothermia with circulatory arrest: determinants of stroke and early mortality in 656 patients. J THORAC CARDIOVASC SuRg 1993;106:19-31.

3. Davis EA, Gillinov AM, Cameron DE, Reiz BA. Hypothermic circulatory arrest as a surgical adjunct: a 5-year experience with 60 adult patients. Ann Thorac Surg 1992;53:402-7.

4. Bachet J, Guilmet D, Goudot B, et al. Cold cerebroplegia. J THORAC CARDIOVASC SURG 1991;102:8594.

5. Kazui T, Inoue N, Yamada O, Komatsu S. Selective cerebral perfusion during operation for aneurysms of the aortic arch: a reassessment. Ann Thorac Surg 1992;53:109-14.

6. Ueda Y, Miki S, Kusuhara K, Okita Y, Tahata T, Yamanaka K. Surgical treatment of aneurysm or dissection involving the ascending aorta and aortic arch, utilizing circulatory arrest and retrograde cerebral perfusion. J Cardiovasc Surg 1990;31:553-8.

7. Safi HJ, Brien HW, Winter JN, et al. Brain protection via cerebral retrograde perfusion during aortic arch aneurysm repair. Ann Thorac Surg 1993;56:270-6.

8. Takamoto S, Matsuda T, Harada M, Miyata S, Shimamura $Y$. Simple hypothermic retrograde cerebral perfusion during aortic arch replacement: a preliminary report on two successful cases. J THORAC CARDIOVASC SURG 1992;104:1106-9.

9. Yamashita C, Nakamura H, Nishikawa $Y$, Yamamoto S, Okada M, Nakamura K. Retrograde cerebral perfusion with circulatory arrest in aortic arch aneurysms. Ann Thorac Surg 1992;54:566-8.

10. Amarasena GAC, Parry AJ, Johnston B, Pillai R. Continuous retrograde cerebral perfusion during an aortic arch operation. Ann Thorac Surg 1993;55: 1566-7.

11. Usui A, Oohara K, Liu T, et al. Determination of optimum retrograde cerebral perfusion condition. J THORAC CARDIOVASC SURG 1994;107:300-8.

12. Mark JB, FitzGerald D, Fenton T, et al. Continuous arterial and venous blood gas monitoring during cardiopulmonary bypass. J THORAC CARDIOVASC SURG 1991;102:431-9.

13. Asano T, Johshita H, Koide T, Takakura K. Amelioration of ischemic cerebral oedema by a free radical scavenger, AVS: 1,2-bis(nicotinamido)-propane-an experimental study using a regional ischemia model in cats. Neurol Res 1984;6:163-8.

14. Croughwell N, Smith LR, Quill T, et al. The effect of temperature on cerebral metabolism and blood flow in adults during cardiopulmonary bypass. $\mathrm{J}$ THORAC CARdIOVASC SURG 1992;103:549-54.

15. Mault JR, Ohtake S, Klingensmith ME, Heinle JS, Greeley WJ, Ungerleider RM. Cerebral metabolism and circulatory arrest: effects of duration and strategies for protection. Ann Thorac Surg 1993;55:57-64.

16. Schell RM, Kern FH, Greeley WJ, et al. Cerebral blood flow and metabolism during cardiopulmonary bypass. Anesth Analg 1993;76:849-65.

17. Mezrow CK, Sadeghi AM, Gandsas A, et al. Cerebral blood flow and metabolism in hypothermic circulatory arrest. Ann Thorac Surg 1992;54:609-16.

18. Anstadt MP, Tedder M, Hegde SS, et al. Pulsatile versus nonpulsatile reperfusion improves cerebral blood flow after cardiac arrest. Ann Thorac Surg 1993;56:453-61.

19. Siesjo BK. Pathophysiology and treatment of focal cerebral ischemia: part II-mechanisms of damage and treatment. J Neurosurg 1992;77:337-54.

20. Pellegrini-Giampietro DE, Pulsinelli WA, Zukin RS. NMDA and non-NMDA receptor gene expression following global brain ischemia in rats: effect of NMDA and non-NMDA receptor antagonists. J Neurochem 1994;62:1067-73. 
21. Ohtaki M, Tranmer B. Pretreatment of transient focal cerebral ischemia in rats with the calcium antagonist AT877. Stroke 1994;25:1234-40.

22. Koide T, Gotoh O, Asano T, Takakura K. Alterations of the eicosanoid synthetic capacity of rat brain microvessels following ischemia: relevance to ischemic brain edema. J Neurochem 1985;44:85-93.

23. Yang $\mathrm{G}$, Chan $\mathbf{P H}$, Chen $\mathrm{J}$, et al. Human copper-zinc superoxide dismutase transgenic mice are highly resistant to reperfusion injury after focal cerebral ischemia. Stroke 1994;25:165-70.

24. Uchiyama-Tsuyuki $\mathrm{Y}$, Araki $\mathrm{H}$, Yae $\mathrm{T}$, Omoto $\mathrm{S}$. Changes in the extracellular concentrations of amino acids in the rat striatum during transient focal cerebral ischemia. J Neurochem 1994;62:1074-8.
25. Yang G, Chan PH, Chen SF, Babuna OA, Simon RP, Weinstein PR. Reduction of vasogenic edema and infarction by MK-801 in rats after temporary cerebral ischemia. Neurosurgery 1994;34:339-45.

26. Rosenbaum DM, Kalberg J, Kessler JA. Superoxide dismutase ameliorates neuronal death from hypoxia in culture. Stroke 1994;25:857-63.

27. Ravussin P, Archer DP, Tyler JL, et al. Effect of rapid mannitol infusion on cerebral blood volume. J Neurosurg 1986;64:104-13.

28. Hartwell RC, Sutton LN. Mannitol, intracranial pressure, and vasogenic edema. Neurosurgery 1993;32: 444-50.

\section{Availability of Journal back issues}

As a service to our subscribers, copies of back issues of The JOURnal of Thoracic AND Cardiovascular SuRgery for the preceding 5 years are maintained and are available for purchase from the publisher, Mosby-Year Book, Inc., at a cost of $\$ 12.00$ per issue. The following quantity discounts are available: $25 \%$ off on quantities of 12 to 23 , and one third off on quantities of 24 or more. Please write to Mosby-Year Book, Inc., Subscription Services, 11830 Westline Industrial Drive, St. Louis MO 63146-3318, or call (800)453-4351 or (314)453-4351 for information on availability of particular issues. If unavailable from the publisher, photocopies of complete issues are available from University Microfilms International, 300 N. Zeeb Rd., Ann Arbor, MI 48106, (313) $761-4700$. 